\title{
Incentive schemes for bank branch staff during deep recession: empirical evidence from Greece
}

\section{Georgios Koutsoukos*}

\author{
School of Social Sciences, \\ Hellenic Open University, \\ 18 Parodos Aristotelous Str., 26335, Patra, Greece \\ Email: gakoutsoukos@eurobank.gr \\ *Corresponding author
}

\section{Anastasios Magoutas}

General Department,

National and Kapodistrian University of Athens,

Location Skliro, 34400, Psachna, Greece

Email: amagoutas@uoa.gr

\section{Panos Chountalas}

Department of Business Administration, University of Piraeus,

80 M. Karaoli \& A. Dimitriou Str., 18534 Piraeus, Greece

Email: pchountalas@unipi.gr

\begin{abstract}
Incentive schemes have been extensively used in the banking sector, though in the years following the world financial crisis a great deal of criticism has emerged, focusing mainly on their contribution to mis-selling and short-termism. This study attempts to explore the incentives field in the current Greek banking context which has been through a massive and arduous transformation in order to avoid collapsing. The questions posed refer to the purposefulness of an incentive scheme in the current Greek banking setting as well as to the design attributes of the optimal incentive scheme for such conditions. To this end, a survey of Greek bank branches' employees was undertaken $(\mathrm{N}=227)$, in order to examine their exposure as well as their attitudes towards incentive schemes. The data analysis suggested that an incentive scheme could still have a position in the Greek banks, even in times of deep recession, provided that it is appropriately designed in order to enhance performance and protect against the risk of mis-selling.
\end{abstract}

Keywords: incentive scheme; banking sector; branch staff; employee attitude; deep recession; Greece.

Reference to this paper should be made as follows: Koutsoukos, G., Magoutas, A. and Chountalas, P. (2020) 'Incentive schemes for bank branch staff during deep recession: empirical evidence from Greece', Int. J. Decision Sciences, Risk and Management, Vol. 9, Nos. 1/2, pp.1-22. 
Biographical notes: Georgios Koutsoukos holds a Master of Business Administration (MBA) from the Hellenic Open University and a Bachelor's degree in Marketing from the Athens University of Economics and Business. $\mathrm{He}$ is an experienced executive in the financial services sector, currently working at Eurobank, one of the major Greek Banks, as Head of retail incentives and performance optimisation. He has also worked in marketing and sales departments of fast moving consumer goods (FMCG) multinational companies like Unilever and Jacobs-Douwe Egberts (ex. Sara Lee). His current business interests include incentive programs, process and MIS optimisation, digital transformation as well as people management and development, while his research interests include incentives, leadership and change management.

Anastasios Magoutas is an Associate Professor at the University of Athens (General Department) and adjunct faculty member at the Hellenic Open University (School of Social Sciences). Prior to his academic posting, he worked as an Administration Manager at the Greek Organization Against Drugs (OKANA). He holds a PhD in Applied Economics from the School of Social Science of the Hellenic Open University and a Master of Business Administration (MBA) from the University of Glamorgan in Wales. His current research interests include human capital and education, tourism planning and policy-making, strategic management and technological innovation.

Panos Chountalas is a Teaching Associate at the University of Piraeus (Department of Business Administration) and a member of the Adjunct Faculty at the Hellenic Open University (School of Social Sciences). He holds a PhD MBA, and a BSc in Business Administration from the University of Piraeus. His scientific publications have appeared in reputed international refereed journals. He has an extensive professional experience in business consulting and has been a researcher in various funded international research projects. His current research interests include tourism management, tourism service quality, and destination marketing.

\section{Introduction}

Performance incentives have been both a business practice as well as an academic field for a long time. In an ideally assumed environment, incentive schemes provide the necessary motivation for employees to perform at their maximum, add the highest value to their customers and boost the employer's performance (Holtmann and Grammling, 2005; Pratheepkanth, 2011; Akhtar et al., 2014; Faisal Ahammad et al., 2015). The employees themselves get rewarded for their exceptional performance and as their satisfaction increases, their motivation becomes gradually intrinsic.

Even if incentive schemes' service is more or less justifiable in healthy and prosperous markets and profitable companies, it is much less reasonable in declining markets and companies with financial losses. Especially in the banking sector, incentives have attracted much criticism in recent years. From Australia (Yeates and Eyers, 2016) to the USA (Board of Governors of the Federal Reserve System, 2011) and from the UK (Financial Services Authority, 2013) to the G-20 forum (G20/OECD Task Force on Financial Consumer Protection, 2013) the way that incentive schemes were designed and operated has been found to be one of the factors that led to the world financial crisis of 2008. Regulators and auditing institutions publish guidelines about the design of 
incentives in the banking industry in order to protect consumers, and in some cases, banking institutions have been fined about their programs (Financial Conduct Authority, 2013a).

As a result of the financial crisis along with the country's inherent financial weaknesses and poor governmental actions, the Greek banking industry has suffered a shocking transformation over the last eight years. Liquidity problems, a sovereign debt restructuring causing huge once-off losses, consolidating programs, recapitalisation through state aid with strict restrictive terms, divestments and downsizing outline the operating framework (Provopoulos, 2014; European Commission, 2015a, 2015b, 2015c). Moreover, the persisting difficult financial situation of the country led to an increasing problem of non-performing loans which changed further the banks' orientation. A drastic decrease in the numbers of both branches and staff as well as tough new challenges emanating from the technological developments complete the picture.

All these facts constitute a rather hard case to deal with, both for the employees who have seen their job changing, their compensation worsening and their career prospects fading, as well as for the employers who need to find ways to return to profits in a continuously changing but constantly hard environment. Taking this situation into consideration it sounded at least strange to talk about incentive schemes for the Greek banks. Nevertheless, incentive schemes do exist in the Greek banks in one form or another. The fact that Greek banks tried to preserve their incentive schemes at the same time that they were forced to cut on branch and employee numbers was intriguing enough in order to investigate the reasons for this decision.

The objective of this paper is to assess whether an incentive scheme would be an advisable option for Greek banks and to explore the various attributes that this incentive scheme should have in order to best fit the Greek banks' needs. Taking into consideration that incentive schemes are usually addressed to sales teams as well as the fact that bank branch positions are distinguished from back-office positions, a focus on the branch network staff was pursued. In order to explore the ways that incentive schemes affect Greek bank branch employees as well as their attitude towards them, an empirical survey was conducted through questionnaires; in total, 227 valid responses were collected.

The remainder of this paper is organised as follows. Sections 2, 3 and 4 present the background of this study by reviewing the literature on the types of incentive schemes, as well as the case for and against incentive schemes. Section 5 presents the research question and hypotheses and Section 6 outlines the methodology employed in this study. Section 7 presents the research results and Section 8 contains a discussion on incentive scheme design and the program's implementation. Section 9 concludes and presents the limitations of the study along with suggestions for future research.

\section{Types of incentive schemes}

The most usual classification of incentive schemes refers to the types of rewards that these schemes involve. A first approach distinguishes monetary from non-monetary rewards. Monetary rewards are rather popular among employees (Burton, 1991) and have been found to be a strong motivator in studies about bank employees' motivation (Akhtar et al., 2014; Omollo, 2015). Non-monetary rewards according to other studies (Cheema et al., 2013) may serve as an equally good or even better motivator than financial 
rewards. A survey conducted by McKinsey reveals several non-monetary rewards to be perceived as stronger motivators than money (Dewhurst et al., 2009) while Locke and Latham (2004) argue that non-monetary rewards may be supporting to financial ones.

Monetary rewards include cash bonuses given on an annual, semester, month or even ad hoc basis for achieving specific results as well as merit pay in the form of annual base salary increases according to the employee's performance. Non-monetary rewards include rewards of a rather symbolic value such as recommendation letters, thank you letters, badges, trophies, dinners with the top-level management, public praise, or personal gifts (Holtmann and Grammling, 2005) as well as rewards that aim to increase intrinsic motivation, like training, choice of tasks, job rotation or challenging work assignments (Dessler, 2013).

As Sharma (2013) suggests for the banking industry, there may be an extensive list of benefits, both short and long-term from which employees or their managers will be allowed to select. Short-term incentives achieve a direct link between the desired behaviour and the reward while long-term incentives exert less pressure on employees, securing thus a better working environment (Holtmann and Grammling, 2005). Especially for the banking industry, where good service quality and trust are considered as key success factors (Gibbs, 1993) long-term rewards contribute to higher quality of service as they provide the necessary time for the employees to be exposed to the outcome of their work. Being exposed to the results of their professional behaviour and performance, employees are supposed to be motivated to act ethically (Phelan and Clement, 2009).

\section{The case against incentive schemes}

Surprisingly enough, even among the opponents of incentives, their effectiveness is not particularly questioned, perhaps due to the plans' evaluation limitations as well (Weinberger, 2005). A few exceptions to this are the study of Skaggs et al. (1991) where performance is threatened by the lack of autonomy that incentives impose as well as the research of Bouranta et al. (2005) that found only weak correlation between incentives and business performance of Greek banks. Another aspect of their ineffectiveness deals with the fact that employees get used to the incentive schemes, take them for granted and forget their essence, making thus their motivational effect short (Aktar et al., 2012; Omollo, 2015). Other drawbacks of incentive schemes include a bias toward short-termism (Coates et al., 1995) and their failing to actually connect reward to performance rather than connecting it to the position held, resulting in perceptions of unfairness (Holtmann and Grammling, 2005).

As Skaggs et al. (1991) argue, when the emphasis is put on the reward, employees may narrow their activity on just the necessary tasks in order to qualify for it. Danilov et al. (2013) provide evidence on the above assumption. Moreover, the existence of incentives schemes has been found to be correlated with unethical behaviour (Denis et al., 2006; Gilespie and Dietz, 2009; Danilov et al., 2013; Nienaber et al., 2014). Specifically, studies show that when monetary rewards exist, a percentage of the population may lie either to customers or to supervisors, especially when they perceive that the likelihood of being caught up is small (Gneezy et al., 2013; Conrads et al., 2013; Gibson et al., 2013; Fischbacher and Föllmi-Heusi, 2013). 
If the issue of unethical behaviour and low quality of performance is approached under the perspective of the banking industry, then the crucial issue of mis-selling emerges. When the customer needs advice on his or her decision there is a risk that the employee may misadvise the customer in order to buy the product or service that will lead to the achievement of his or her targets and give the higher commission instead of helping the customer to realise which product best suits his or her needs (Inderst and Ottaviani, 2009; Popova, 2010; Angelova and Regner, 2013).

The world federation for consumer rights 'Consumers International' on its report by Lindley (2014) illustrates the involvement that banks' incentives schemes have in mis-selling financial products: the shift of banking culture from customer relationship-oriented to sales oriented has caused problems through establishing sales targets and the corresponding incentive schemes. This, in turn, has affected the whole procedure of sales, starting from the design of products, continuing to their communication by branches' staff and ending with poor after sales service and complaints handling. According to the writer, sales incentive schemes promote high-risk activities and short-term gains and are part of the reasons that led to the financial crisis of 2008.

The findings of the Consumers International Report are supported by publications stating both cases of problems created by incentive schemes in banks as well as a trend to deal with them in terms of legislation and business practice. The UK-based Financial Services Authority (FSA) which was later transformed to the Financial Conduct Authority (FCA), announced some years ago a series of actions towards the review and reform of the banks' incentive schemes in order to secure customers' interests (Bachelor, 2012; Wheatley, 2012). This inspection led to a fine of $£ 28$ million for Lloyds TSB Bank plc and Bank of Scotland plc (Financial Conduct Authority, 2013b). Following these actions, a number of banks, including Barclays, Lloyds, HSBC, Royal Bank of Scotland and TSB Bank changed their incentive schemes, aiming to replace sales focus with customer service orientation (Goff, 2012; Dunkley, 2014). Nevertheless, even after the corrective actions, there is scepticism regarding the profoundness and essence of culture change in banks (Hyde, 2014).

\section{The case for incentive schemes}

The prevalence of incentive schemes in the majority of contemporary firms, including the financial sector businesses is an indication of their effectiveness in enhancing productivity and performance of employees (Jenkins et al., 1998). A series of studies have shown the linkage between incentive schemes, motivation and performance in the banking industry (Holtmann and Grammling, 2005; Pratheepkanth, 2011; Akhtar et al., 2014; Faisal Ahammad et al., 2015). Motivation is linked both with the increase of employee satisfaction (Jehanzeb et al., 2012; Priya and Eshwar, 2014; Payne et al., 2000), perceived organisational support (Hassan et al., 2014) and commitment (Malhotra et al., 2007). Moreover, incentive schemes help in making the firm's strategy and goals clearer for employees both generally (Zingheim and Schuster, 2000) as well as specifically in the banking sector (Burton, 1991; Holtmann and Grammling, 2005; Lindley, 2014). Resulting from the above effects is the improvement of overall business performance (Lawler, 2005; Umrani and Mahwood, 2015; Brown, 2008). 
Regarding the drawbacks of incentive schemes stated in the previous section, evidence provided against many of the reproaches charged to incentive schemes may be found in contrary studies. Incentive schemes through enhancing satisfaction and creating a perception to the employees that they are treated well and taken care of, seem to contribute to improved customer service and satisfaction (Schneider and Bowen, 1985; Chebat et al., 2002; Papasolomou and Vrontis, 2006; Hyż, 2010; Jeffrey and Wilches-Alzate, 2014; Mendoza and Maldonado, 2014). Extending this approach, the reports by Bryson et al. (2012) and Lindley (2014), comment on the power of incentive schemes to form and give direction to a company's culture, making them thus a powerful tool in achieving a series of organisational goals when it is properly designed and implemented.

This latest statement supports the findings of Eisenberger and Cameron's (1996) analysis of numerous researches on rewards. The writers argue that the problems deriving from incentive schemes are due to specific conditions that are easily avoidable while the benefits from them are easier to achieve. Their approach, that everything is a matter of design and implementation is consistent with the comment that the actual problem with incentive schemes is that they are too effective (Baker et al., 1988). As the writers argue, a strong incentive scheme makes the employee perform exactly the way he or she is told to, so it is a matter of what is asked through the incentive scheme. Cadsby et al. (2010) in their experiment about the effects of financial incentives on unethical behaviour observed that cheating may be avoided without having to drop performance-related pay. Incentive schemes are powerful tools and as such, they should be treated.

\section{Research question and hypotheses}

This study is guided by the following overarching research question:

- How an incentive program for the employees of Greek bank branches should be - if at all in order to fit to and serve the needs of the current conditions in the Greek banking system?

Taking into consideration both the difficult financial position of the Greek banks that was described above, as well as the dissension over the incentive plans' purposefulness and effectiveness, it is evident that their costs should be fully justified by their outcomes.

The motivation of employees is admittedly the first expected outcome of an incentive program. Pratheepkanth (2011) in his research finds a high correlation (i.e., 0.755) between rewards and motivation of bank employees while Omollo (2015) notes that 90\% of the bank employees in his study state that the incentive scheme of their bank is highly motivating. Therefore, some key research hypotheses addressed are:

- Incentive schemes have a positive influence on Greek bank employees' motivation, satisfaction, commitment and productivity.

- Incentive schemes do not have a negative influence on the quality of Greek bank employees' performance and do not lead to mis-selling.

Having examined whether an incentive plan would be prudent in the current Greek banking context, the next question that arises is how this incentive plan should be designed. Within this context, a number of issues are addressed: 
- What should be the criteria for reward in an incentive plan for Greek banks? Effort, results achievement, sales, superior customer service, hard work, solidarity are examined.

- What kind of rewards should an incentive plan for Greek banks have? Direct cash payments, points collected towards prizes, deposits to pension plans, experience gifts, prises, precedence for promotion, precedence for salary raise, precedence for transfer to branch with better proximity to home, training of employee's choice, symbolic rewards, and family reward are assessed by the participants.

- How big in relation to the basic payment should the rewards of incentive plans for a Greek bank be?

- Should an incentive plan for Greek banks be fixed for all employees or should it be adapted to the needs of various employee groups?

- $\quad$ And finally, are there any statistically significant differences among Greek bank employees, depending on their gender, age, education level, employment time in the banking sector, position, the bank they work for, salary level?

\section{Methodology}

The first decision regarding methodology is whether the research will be a quantitative or qualitative one. According to Jonker and Pennink (2010), the determinant of this decision is the type of research question that is set. There is a degree of knowledge construction and originality in the combination of the incentive schemes' attributes but as long as these attributes are a result of testing existing suggestions, the research question may be considered as a closed one, leading to a rather deductive than inductive approach (Greener, 2008). Therefore, a quantitative, descriptive research, employing the survey method, seems to be the appropriate strategy for this study.

Another factor that contributed to this decision is the highly unstable environment of the Greek market over the last eight years. Dramatic changes in the country and its economy, far beyond the reach of Greek banks have substantially influenced their performance almost on a quarterly basis. It is for this exact reason that the scope of the study confines to a 'snapshot' of the current situation making it thus a cross-sectional study.

A self-administered questionnaire was constructed for the purposes of the survey. A series of issues had to be dealt with during the design of the questionnaire, regarding mainly its reliability and validity. A pilot-test of the questionnaire on a sample of about 20 respondents took place, which led to further refinements. The questionnaire included 50 questions and consisted of six parts, forming six successive pages. The average time needed to complete it was about ten minutes, as measured on its testing by the sample group. In order to save space, extensive use of matrix questions was chosen after confirming with trial completions that their format was understandable by the respondents. The questionnaire was created using the Google Forms tool following a rather neat and clean template and was hosted on the same platform. It consisted of questions about the respondents' attributes, tested their knowledge about various incentive schemes and also included a question about the existence of an incentive 
scheme in the bank they work for. It further asked about the incentive scheme in their bank, their opinion about incentive plans, as well as their preferences on the ideal incentive scheme.

The questionnaire was administered through the web and its link was both mailed to employees of banks as well as posted to various social pages of banking professionals, like banking unions and banking postgraduate programs and alumni. The final result was 227 completed and usable questionnaires out of a total of 231 respondents.

The sample had sufficient dispersion among banks, positions in the branch, ages, salaries, and other attributes. More specifically, almost $60 \%$ of the respondents were women with the rest $40 \%$ representing the male respondents. Most respondents' age was between 30 and 40 years $(68.7 \%)$. A bit less than half of the respondents have a banking work experience of fewer than ten years while another $45 \%$ of the respondents' work experience is set between 10 and 20 years. Moreover, all the typical positions of a Greek bank branch are represented with percentages ranging from $4.4 \%$ for the non-performing-loans officers to $16.7 \%$ for customer service of small business banking officers. Most of the respondents (39.2\%) declared a monthly salary between $€ 1,301$ and $€ 1,800$ while the salary range of less than $€ 1,300$ and that of $€ 1,801$ to $€ 2,500$ were also significantly represented with $32.6 \%$ and $20.7 \%$ respectively.

The choice of analysis techniques was made on the basis of both the type of data available as well as the research objectives. Firstly, an exploratory analysis of the individual variances was conducted, as suggested by Saunders et al. (2009), in order to get a first view of the data and finalise the next steps of the analysis. Frequency tables and charts were used in order to describe the data collected, while cross-tabulations were employed wherever the results suggested further analysis.

For the part of inferential statistics where the hypotheses were tested, the type of data determined the techniques. Most of the data derived either from Likert scales and individual items or from multiple choice questions. A more strict approach suggests that the distance between 'agree' and 'strongly agree' cannot be measured nor it can be supposed as equal to the distance between 'agree' and 'neither disagree nor agree', therefore the data are ordinal and parametric tests cannot be applied (Clason and Dormody, 1994; Jamieson, 2004).

\section{Results}

\subsection{Descriptive research findings}

The first question checked whether the respondents' employer bank had an incentive scheme. The results revealed that $47.6 \%$ of respondents currently have an incentive program, $37 \%$ had one in previous year, $8.4 \%$ did not know about the existence of such a program and $7 \%$ stated that never such a program existed.

The next set of questions for the respondents that had positively answered the question regarding the existence of incentive schemes in their employer bank explored the attributes of these schemes. The first of these questions regarded the types of rewards that the incentive schemes use or have used in the past. The most popular answer was cash payment $(88.5 \%)$, followed by prizes $(43.2 \%)$, promotion $(29.2 \%)$, and symbolic $(21.4 \%)$. 
Another aspect that needed to be examined was whether the existing incentive schemes were regular programs or had a more ad-hoc approach, like a sales contest. More than half of the respondents $(51.6 \%)$ stated that both regular plans, as well as ad hoc programs, are carried out by the Greek banks. Almost 32\% of the respondents stated that their bank has only ad hoc programs and only $16.7 \%$ stated that their bank's incentive scheme is a regular one.

The next questions were designed to investigate the extent to which the respondents who have declared that their bank has or used to have an incentive scheme have themselves been rewarded with some form of reward. Most employees have received some form of reward, while $37.5 \%$ of them state that they receive rewards frequently and another $26 \%$ declare that they receive rewards occasionally. Apart from the occurrence of being rewarded from an incentive scheme, the size of the reward, as a percentage of total pay was also considered. Almost the two-thirds of the sample responded that the rewards were less than $5 \%$ of their total payment. An analysis per position shows that higher rewards tend to be given to the branch and platform managers as well as to the non-performing loans officer.

Figure 1 Problems of existing incentive schemes of the Greek banks (see online version for colours)

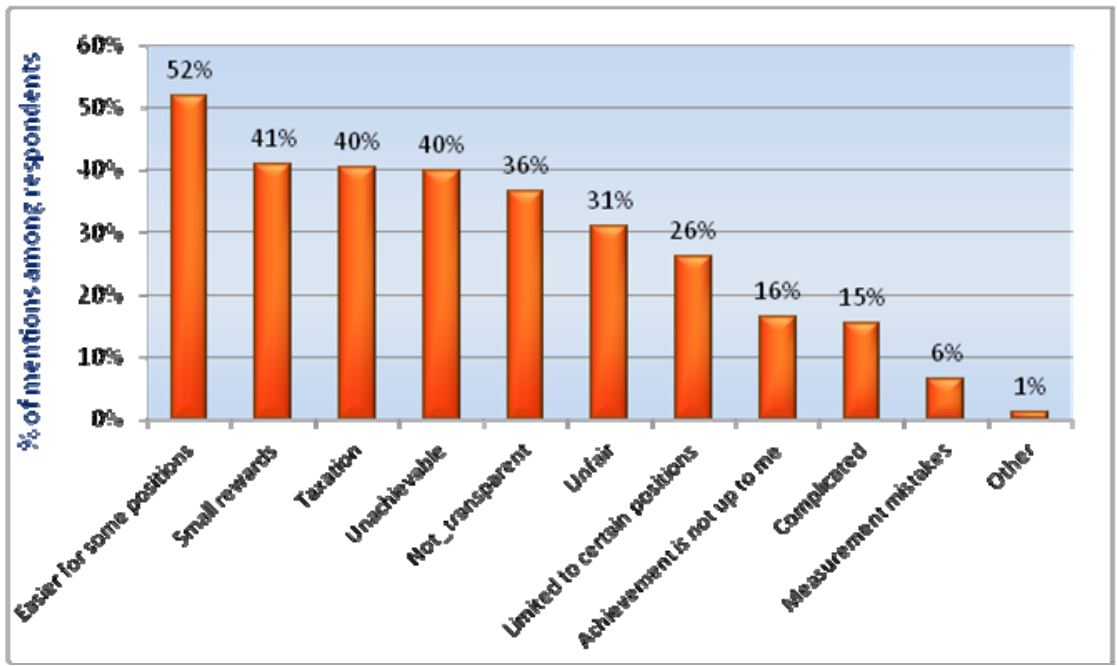

The employees' perception of the existing incentive schemes' problems is of particular interest as it can give valuable information on the design of a new scheme (see Figure 1). The analysis of the responses shows that the most frequent problem, mentioned by more than half of the sample, was that not all positions in the branch have the same opportunity in getting a reward which was further analysed that for some positions it is easier to achieve the target and claim the reward as compared to others. The teller and the mortgage officer score significantly higher on this response, while positions that are currently better rewarded, like the non-performing loans officer do not perceive this inequality as an issue. Other significant problems included the small rewards, the taxation, the difficulty to achieve, and the lack of transparency. 


\subsection{Attitudes toward incentive schemes}

The next part of the questionnaire was designed to explore the effects of incentive schemes to Greek bank employees regarding various aspects studied in the literature. First, as regards the respondents' distribution on the motivational effect of incentive schemes, almost $60 \%$ of the sample stated that incentive schemes had a positive influence on their motivation while only $21 \%$ argued the opposite.

The next questions on attitudes towards incentive schemes refer to work satisfaction, work stress and perception of solidarity. The majority of the responses (70\%) appear in the 'agree/strongly agree' categories regarding the general satisfaction question, with only $13 \%$ being in the opposite side. Regarding the work stress aspect, a mixed status is apparent. The most often appearing option is the neutral one (neither agree nor disagree), while the rest of the responses are equally split between the positive and negative edges. The solidarity question has also a dispersion among responses, with a slight predominance of the 'agree/strongly agree' edge which gives a negative quality on incentive schemes, but with a significant presence of the neutral and positive (disagreement) responses as well.

Next, the respondents were asked to state their level of agreement to the statement that the existence of an incentive scheme would be an important criterion for employer choice. While the response that appears more often (mode) is the neutral one (32\%), there is a clear predominance of the agreement side with almost $43 \%$ over the disagreement side $(25 \%)$. Furthermore, the respondents were asked to reveal whether the quantity of their work was positively influenced by incentive schemes. Again, even though the neutral answer is the most frequent, the positive answers (agree and strongly agree) were almost $46 \%$ of the sample, that is a double value compared to the negative answers $(23 \%)$.

Figure 2 Reward criteria of an ideal incentive scheme for Greek banks (see online version for colours)

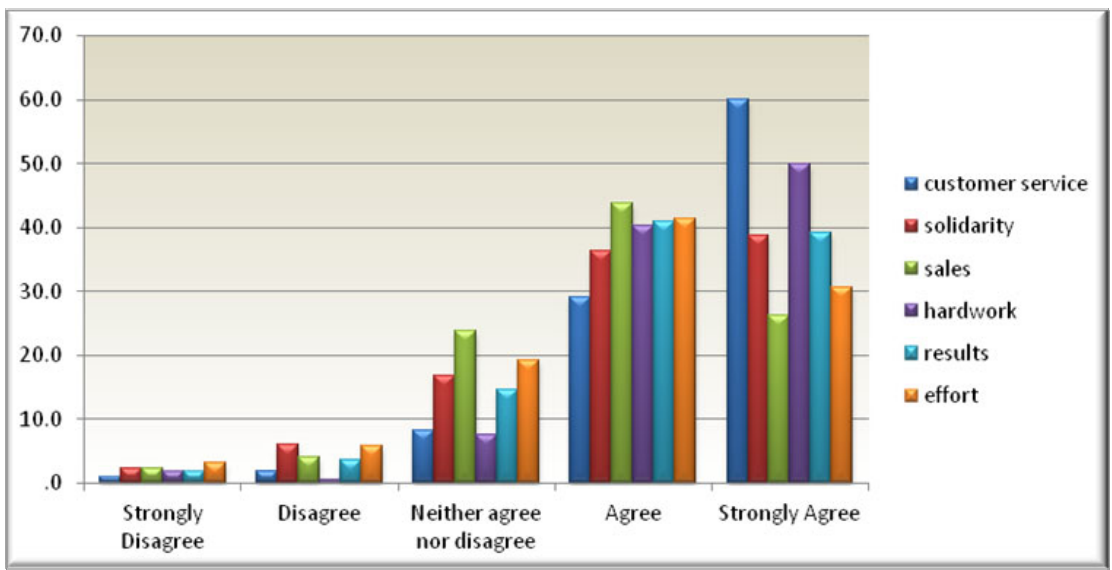

Another interesting finding was that while the respondents consider that the quality of their work is not negatively affected by incentive schemes $(60 \%)$, when the question becomes more specific regarding the nature of bad quality (mis-selling) - but less specific regarding the person whose performance is of low quality - the responses are 
almost reversed, with $46 \%$ agreeing with the statement and $33 \%$ having a neutral position.

The respondents were also asked to give the degree of agreement with statements about the orientation of an ideal incentive scheme. As all the suggestions of the survey were accepted by the respondents, a summary chart should be helpful in making any comparison among them (see Figure 2). A first visual assessment of the chart shows that the 'customer service' and 'hard work' criteria are particularly popular, followed by the 'results' and 'solidarity' criteria. It seems that the 'ideal incentive scheme' as regarded by the Greek bank employees should fit an 'ideal bank', where excellent customer service and hard work along with solidarity would make up the ingredients for superior results.

Regarding the adaptation of the incentive scheme to each different position in the branch - as opposed to a common program for everybody - the employees working in the branch network of the Greek banks have a strong preference towards an incentive scheme specifically designed and adapted to each position. $79 \%$ of the sample agree or strongly agree with such a format while only $6 \%$ of the sample disagree or strongly disagree.

Figure 3 Importance of various incentive schemes' attributes (see online version for colours)

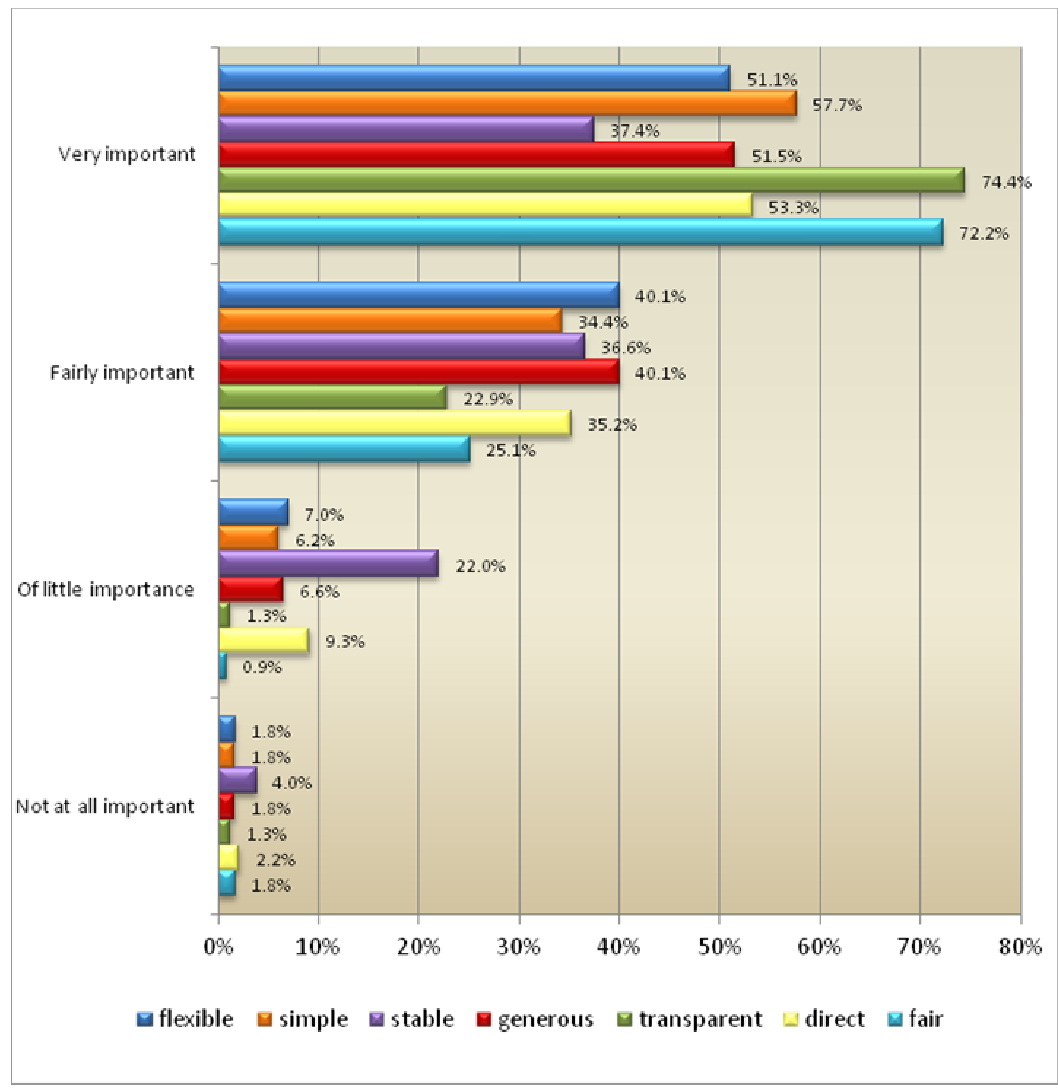

In the next set of questions, the respondents were given various attributes that an incentive scheme could have and were asked to state how important each attribute was to them. The attributes given were transparent (i.e., everyone knows the rules of the 
program), simple, generous (i.e., the rewards are significant to the employee), direct (i.e., everyone knows each moment whether he or she wins, as well as the type and size of reward achieved), stable (i.e., without frequent changes), flexible (i.e., having the ability to be adapted to each period or even each branch) and fair (i.e., the reward goes to the one who actually did the job). Figure 3, visualising the frequencies of the responses for each attribute, reveals that all of the attributes are important to the Greek bank employees. Transparency and fairness are the most desirable attributes of the ideal incentive scheme for the Greek banks, being considered as very important by $74.4 \%$ and $72.2 \%$ of the sample respectively, followed by simplicity which is considered as very important by $57.7 \%$ of the sample. On the other hand, stability, though considered fairly important or very important by $74 \%$ of the respondents, is the less desirable attribute, a result rather consistent with the higher importance given to flexibility.

The size of the ideal incentive scheme was measured in terms of the preferred variable pay proportion over total payment. The respondents were given an example saying that if a fixed monthly salary of $€ 1,000$ was replaced by $50 \%$ variable payment, that would mean that a bad performance would result in getting paid only $€ 500$ (the fixed part), a fair performance would mean that the payment would be $€ 1,000$ and an exceptional performance would result in a payment of $€ 1,500$. According to this example, they were asked to give the desirable proportion of the variable, performance-related payment. The average variable pay proportion that the sample stated was $24.47 \%$ of the total payment, while the median and mode were $20 \%$. Figure 3 reveal that Greek bank employees desire a much larger variable pay proportion (between $21.82 \%$ and $27.12 \%$ ) compared to the current situation (variable pay is less than $5 \%$ of total).

\subsection{Inferential statistics}

In this section, inferential statistics are employed in order to draw conclusions about the relationship of incentive schemes to the population of employees who work at the Greek banks' branch networks.

Greek bank employees perceive that incentive schemes have a positive influence on their motivation, satisfaction, commitment, and productivity. In contrast, the hypothesis that Greek bank employees perceive that incentive schemes increase their work stress is not supported. Moreover, Greek bank employees perceive that incentive schemes do not have a negative influence on the quality of their performance, but do lead to mis-selling. Furthermore, they perceive that incentive schemes should use all the suggested criteria (i.e., effort, results achievement, sales achievement, customer service, hard work, solidarity) in order to evaluate and reward them. All the aforementioned hypotheses were tested using the one-sample Wilcoxon signed rank test at a 5\% level of significance.

Taking the above findings into consideration, the need to further investigate the issue of the ideal incentive scheme's evaluation criteria emerges. Since all the criteria are found to be important by the Greek bank employees, it is a reasonable thought to examine their relative importance and rank them according to it. A Friedman test reveals whether the responses on each of the proposals have a similar distribution or there are differences. The corresponding results suggest that the differences between the preferences on evaluation criteria of the ideal incentive scheme by the Greek bank employees are statistically significant $\left(x_{(5, N=212)}^{2}=114.48, p<.001\right)$. Moreover examining the 
distribution of preferences on each suggestion, as well as their mean rank, we conclude that the proposed evaluation criteria form three groups of preferences, according to their importance (ranked from more to less important):

1 customer service and hard work

2 results achievement and solidarity

3 effort and sales achievement.

The above findings may be visually summarised in Figure 4.

Figure 4 Ranking of evaluation criteria for the ideal incentive scheme (see online version for colours)

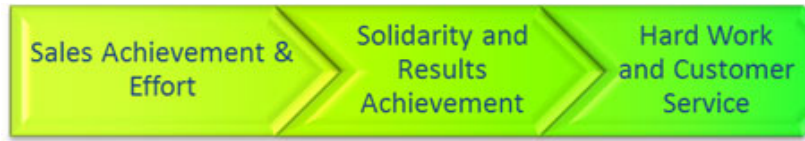

Figure 5 Frequencies of responses on the rewards of the ideal incentive scheme (see online version for colours)

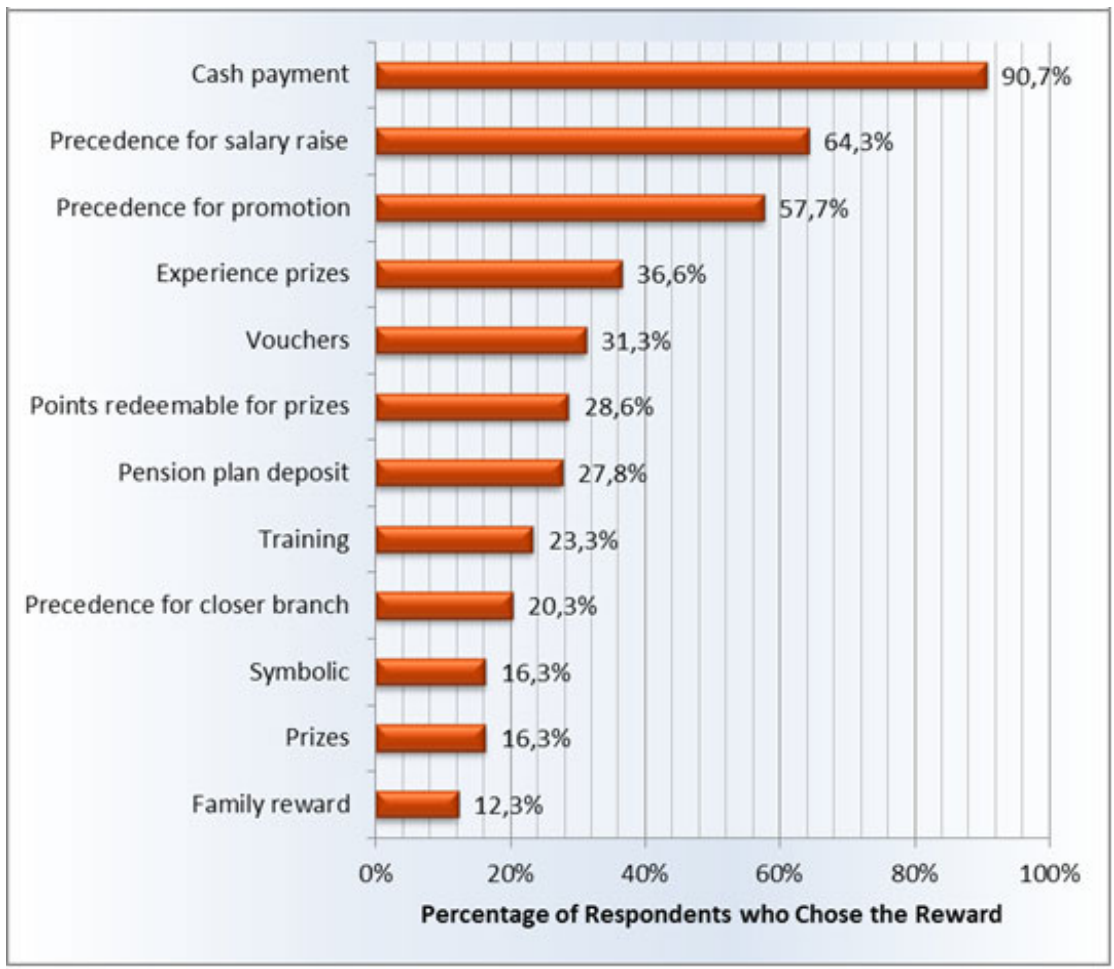

Regarding rewards preferred for the ideal incentive scheme, direct cash payments emerge as the most popular reward type, having been mentioned by $90.7 \%$ of the sample. The next most popular reward types are the precedence for salary raise and precedence for promotion with $64.3 \%$ and $57.7 \%$ respectively. These rewards, even though they score 
quite lower than cash payments, they still score more than $50 \%$, which means that more than half of the sample have chosen them as preferred rewards. Two more reward types, experience prises and vouchers, have scored more than $30 \%(36.6 \%$ and $31.3 \%$ respectively), while the rest rewards score less than $30 \%$. Figure 5 displays the aforementioned results.

Even though all the responses got some support, it is obvious that an incentive scheme cannot have all types of rewards simultaneously. Taking the above frequencies into consideration and 50\% score as a threshold, a binomial test confirms the hypotheses that at a 5\% significance level the reward types that would be preferred by most Greek bank employees are cash payments and precedence for salary raise and promotion. We observe that the first and second rewards are monetary, while the third is non-monetary. At the same time, the first reward is short-term while the other two are long-term oriented. Grouping the responses in short and long-term ones as well as to monetary and non-monetary we observe that monetary rewards have attracted more responses than non-monetary and short-term are more popular than long-term in the survey but both types are significant enough so that it cannot be supported that only one type would be sufficient.

The next set of hypotheses tests whether all the previous findings have differences among various groups such as gender, age, position, previous experience, education, employer bank, and salary tier groups. After conducting all the tests, only the hypotheses that are indeed supported are stated in more detail.

The first criterion that was tested in order to examine whether the responses of the groups formed by it are differentiated is gender, but no such differentiation may be supported.

The next criterion that was tested is age. A Kruskal Wallis test shows that age is indeed correlated with the responses of the sample regarding the effect of incentive schemes on their satisfaction $\left(x_{(2)}^{2}=6.318, p=0.042\right)$ and productivity $\left(x_{(2)}^{2}=9.088, p=0.011\right)$. Younger people (less than 30 years old) have a more positive attitude towards incentives as they seem to agree or strongly agree that incentives increase their satisfaction and productivity more than the older age groups.

The next criterion that was tested is educational level. A Kruskal Wallis test shows that educational level is indeed correlated with the responses of the sample regarding the effect of incentive schemes on their motivation $\left(x_{(2)}^{2}=6.320, p=0.042\right), \quad$ satisfaction $\quad\left(x_{(2)}^{2}=6.404, p=0.041\right) \quad$ and productivity $\left(x_{(2)}^{2}=10.986, p=0.004\right)$. The more educated a bank employee is, the more likely it is that he or she has a positive attitude towards incentives. Postgraduates seem to be more motivated, satisfied and to increase the quantity of their work as a result of incentive schemes more aggressively compared to lower educational levels, while the high school or college graduates are found on the opposite site.

The next criterion that was tested is the length of experience in the banking sector. Regarding the reward types, a chi-square test supports that the Greek employees' preferences vary according to their experience $\left(x_{(24)}^{2}=48.125, p=0.002\right)$.

While cash payments were clearly the most popular reward, more experienced employees asked also for symbolic rewards and training more than the other groups while less 
experienced employees, having been hired just before or during the financial crisis seem to be keener on a permanent salary raise, compared to the other groups.

The next criterion that was tested is the position held by the employee in the branch. A Kruskal Wallis test shows that the position in the branch is indeed correlated with the preferences of the employees over the criteria of effort $\left(x_{(8)}^{2}=16.511, p=0.036\right)$, results achieved $\quad\left(x_{(8)}^{2}=16.601, p=0.035\right) \quad$ and sales achieved $\quad\left(x_{(8)}^{2}=16.200, p=0.04\right)$. Customer service officers and tellers are more positive than others towards the effort criterion for an ideal incentive scheme, while non-performing loans officers are the less positive. Branch managers are the most positive towards the results criterion, while non-performing loans officers are the less positive compared to others. Non-performing loans officers are the less positive towards the sales criterion for an ideal incentive scheme while affluent banking officers and platform managers have the most positive attitude.

The next criterion that was tested is the employer bank of each respondent. A Kruskal Wallis test supports that there is a differentiation among bank on the responses regarding the effect of incentive schemes on motivation $\left(x_{(3)}^{2}=10.863, p=0.012\right)$ satisfaction $\left(x_{(3)}^{2}=14.514, p=0.002\right)$ and productivity $\left(x_{(3)}^{2}=15.719, p=0.001\right)$. The strongest motivational effect was reported by the employees of the bank that makes the smallest use of incentives among the four main banks in Greece, while the employees of the bank that has significantly reduced incentives usage in recent years report the highest levels of satisfaction and productivity increase. On the other hand, the employees of the bank that makes the most extensive usage of incentives seem to be less keen (though positively oriented) than the others, confirming the finding of various studies that employees after a while tend to take incentives' rewards for granted.

The last criterion that was tested is the salary level. The employees' preferences over various reward types are differentiated according to their salary level $\left(x_{(36)}^{2}=68.391, p=0.001\right)$. Although cash payments are clearly the most popular reward,

a permanent salary raise, as expected, is more popular to lower-paid employees while symbolic rewards and experience prises are more popular to the higher-paid employees compared to the other groups.

\section{Discussion on incentive scheme design and program's implementation}

The 'ideal' incentive scheme for Greek banks should fit the preferences and attitudes of their employees, as they were identified in this study.

The incentive scheme's rules must be simple and clear to everyone in order to secure transparency. They should also be formed in a way that the reward will be allocated to the employee that worked for it and deserved it, in order to be perceived as fair. Its rewards should be generous, directly connected with the desirable behaviours and equally addressed to each position in order to surpass the unfairness issue that was addressed in this study and engage all positions and branches. Regarding the generosity aspect, special attention should be given to the taxation issue as taxation has emerged among the most common problems of current incentives. 
Regarding the criteria used in order to evaluate the desirable behaviour, Greek bank employees themselves propose a rather sophisticated and bold approach; superior customer service along with hard work should be the most honoured and rewarded behaviour and its delivery should be the most important criterion in order to be rewarded. This way, the risk of mis-selling is decreased and the benefit for society is enhanced. At the same time, the employer's goals are taken into consideration as well as the employees' well-being by suggesting achievement of results along with solidarity as the next important criteria, while 'dangerous' attitudes, like the sales achievement criterion or 'convenience' choices, like the effort criterion are not preferred. A provocative approach to these preferences would suggest that Greek bank branch employees prove to be wiser than expected and their opinion should be better appreciated by their management teams.

Greek bank employees clearly prefer an incentive scheme that will be tailored and addressed to each different position in the branch. This way, the preferential treatment of positions that was referred to as a problem will be dealt with and the program will involve as many people as possible.

Considering the size of the incentive scheme, Greek bank employees prefer a much larger proportion of their payment to be variable than the existing one. Most respondents answered that their current variable pay is about $5 \%$ of their total pay or less. Nevertheless, the average desired proportion of variable pay was five times higher (about $25 \%$ ). This is a rather high score, especially if one considers the example given in the respective question that did not give any premium to the payment in order to compensate for the uncertainty of it. A first approach to this result could be that Greek bank employees are rather bold or confident in their performance. Nevertheless, a more cautious and pessimistic approach would suggest that Greek bank employees, living in a difficult environment with a negative outlook and having received a serious reduction in their compensation over the last years, could be just desperate. Further research will be needed to clarify this point.

The reward of an ideal incentive scheme is a difficult issue to deal with. Direct cash payments are definitely a popular reward, but taxation and small rewards were also popular problems referred to by the same people. Also, a mix of long and short-term, monetary and non-monetary rewards was preferred by different groups. While the adjustment of other incentive scheme's attributes per employee would not be advisable for the sake of simplicity, fairness, and transparency, the adaptation of reward types to the employees' preferences seems a more reasonable task. Nevertheless, preference over reward types seems to be correlated to several respondents' attributes while some of them like experience or salary level cannot be used directly as discrimination and loss of confidentiality issues emerge. A solution that would fit this situation would be the offering of a variety of rewards from which each employee can choose the one that most prefers. This way, lower-paid employees could choose cash payments or a form of precedence for salary raise, while higher-paid, more experienced employees should have the opportunity to opt for symbolic rewards or experience prises. Such an approach would result in higher levels of engagement as each employee would have the motive to contest for his or her favourite reward. A further cost-benefit analysis should be undertaken, as the enhanced motivation and performance should surpass any logistic problems and costs created by the diversity of rewards, in order for such an approach to be justified. 
Apart from the incentive schemes design, another aspect that should be taken care of is the program's implementation. Specifically, two main issues should be dealt with. Firstly, efficient and intensive communication of the program is necessary in order to ensure that employees are aware of the program and understand it. The variety of answers in the questions about the existence of incentive scheme and its attributes in the respondents' bank revealed that an important part of the employees was not aware of the programs. Follow-up interviews revealed that all banks had some form of incentives, but $15 \%$ of the sample answered that there never existed such a program or that they do not know, while $37 \%$ answered that there was not an incentive after 2014, which was also not right for some cases. Secondly, intense control mechanisms and an overall review should be established in order to ensure that the incentive program does not lead to undesirable behaviour, like mis-selling or manipulation of information.

\section{Conclusions}

The purpose of this paper has been to study the field of incentive schemes and focus on their application in the current Greek banking sector. The review of the respective literature has revealed that the main problem of incentive schemes is focused on their design and implementation rather than their existence itself. Incentives motivate people to perform as they are requested, so a non-desirable behaviour is usually an outcome of wrong design or insufficient control. Following similar research, in this study, the banks' branch network employees' opinion has been the guide on evaluating several aspects of incentive schemes. Having analysed the data collected through the research instrument, a critical and collaborative review of the results offers useful insights on the issue of incentive schemes for the banks operating in Greece.

Drawing from the findings of this study, we may suggest that Greek bank employees who still have an incentive seem to appreciate it less. Further testing on the relationship of the existence of incentives with motivation confirms the validity of this relationship for Greek bank employees. This finding is in agreement with the results of Aktar et al. (2012) and Omollo (2015) who suggested that the incentive plans' motivational effect is rather short, as employees tend to dissociate the rewards from their performance and consider them as given.

Perhaps the most serious problem linked with incentive schemes in banks is the issue of mis-selling (Inderst and Ottaviani, 2009; Popova, 2010; Angelova and Regner, 2013). This study is in accordance with the above argument as Greek bank employees, who are in charge of selling banking products themselves, are likely to believe that incentive schemes do lead to mis-selling. Another drawback of incentive schemes is their bias towards specific positions on the allocation of rewards, failing thus to connect effectively reward to performance and creating perceptions of unfairness (Holtmann and Grammling, 2005). In consistency with the above argument, this study revealed that the preferential treatment of specific positions is regarded as the most common problem of Greek banks' incentive schemes.

On the other hand, it seems that the employees' dissatisfaction due to performance measurement problems referred by Holtmann and Grammling (2005) is not an issue for Greek banks. Moreover, our study suggests that Greek bank employees perceive that the 
quality of their work is not threatened by incentive schemes, so the issue of low quality on performance, as stated by Skaggs et al. (1991) is not supported.

Furthermore, a series of arguments supporting incentive schemes seem to be valid for the Greek case. The increase of motivation is the expected direct outcome of incentive schemes according to several studies (Holtmann and Grammling, 2005; Pratheepkanth, 2011; Akhtar et al., 2014; Faisal Ahammad et al., 2015) and Greek bank employees seem to be no exception on this. The effects of incentive schemes on employees who work for the Greek banks branch network also include an increase in productivity, in work satisfaction as well as enhancement of employees' commitment. These findings are consistent with Jenkins et al. (1998) suggestion about productivity increase, Malhotra et al. (2007) finding about commitment enhancement as well as with several studies about satisfaction increase (Payne et al., 2000; Jehanzeb et al., 2012; Priya and Eshwar, 2014). So, should Greek banks have an incentive scheme for their branch employees or not? It seems that there are benefits that are too important to be ignored but risks should be anticipated and coped with as well. The solution lies in the incentive schemes' design and implementation, as this study clearly showed (see Section 8).

Even though a lot of effort was put in securing the validity, reliability, and usefulness of this study, some points must be stressed. The main limitation of this study derives from its broad scope. Aiming to examine multiple aspects of the incentives field at the same time, this study has been limited to a certain depth of analysis. The research instrument used included items from other, more narrowly focused research works, but has not heavily relied on any of them. This way the results may not be directly compared to other research findings. Moreover, aiming to test a large number of hypotheses resulted in having to content on a small number of items for each question.

A second point that must be stressed is the cross-sectional nature of the study. Even though there were detailed data about the incentive schemes and their results for one of the banks, sufficient enough to support a time-series analysis, this approach was not preferred, in part due to the highly unstable environment that would limit its usefulness but mostly for reasons of information confidentiality and research ethics.

Related to the same reason is the third limitation of this study, which is the exclusive use of the employees' perceptions and attitudes in making conclusions about the banks' incentive schemes. A more complete approach could include the opinions of higher management levels or HR specialists along with the use of secondary data about the various forms of incentives used in the past and their respective results.

Future research could cover these limitations by doing in-depth analysis on each of the issues discussed in this study. Examples are the investigation of the reasons for the lack of awareness that was observed, the research on the implementation of a multiple offering of rewards that was suggested, or an analysis of the reasons for the differences in responses among the four banks examined. Moreover, taking into consideration that an incentive scheme contains and reflects the company's strategy and culture, further research on the strategic alignment of incentives with the company's internal and external environment is needed. Furthermore, the duplication in Greece of existing research made in other countries could provide useful insight into the specific particularities of the Greek case. Last but not least, a couple of months after the completion of this study's questionnaires, Greek banks reported profits for the first time after many years of losses, possibly signalling a change of course for the Greek banking industry. If this positive signal continues and a developmental track is re-established, this study should be repeated in order to examine the effect of the situational change on employees' attitude. 


\section{References}

Akhtar, N. et al. (2014) 'Factors affecting employees motivation in banking sector of Pakistan', Journal of Asian Business Strategy, Vol. 4, No. 10, pp.125-133.

Aktar, S., Kamruzzaman Sachu, M. and Ali, M.E. (2012) 'The impact of rewards on employee performance in commercial banks of Bangladesh: an empirical study', IOSR Journal of Business and Management, Vol. 6, No. 2, pp.9-15.

Angelova, V. and Regner, T. (2013) 'Do voluntary payments to advisors improve the quality of financial advice? An experimental deception game', Journal of Economic Behavior and Organization, Vol. 93, pp.205-218.

Bachelor, L. (2012) The Guardian - FSA to Crack Down on Incentives for Bank Sales Staff [online] http://www.theguardian.com/money/2012/sep/05/fsa-crackdown-incentives-bank-sales-staff (accessed 26 March 2016).

Baker, G.P., Jensen, M.C. and Murphy, K.J. (1988) 'Compensation and incentives: practice vs. theory', The Journal of Finance, Vol. 43, No. 3, pp.593-616.

Board of Governors of the Federal Reserve System (2011) Incentive Compensation Practices: A Report on the Horizontal Review of Practices at Large Banking Organizations, Federal Reserve Board: Washington, DC.

Bouranta, N., Mavridoglou, G. and Kyriazopoulos, P. (2005) 'The impact of internal marketing to market orientation concept and their effects to bank performance', Operational Research, An International Journal, Vol. 5, No. 2, pp.349-362.

Brown, D. (2008) 'Measuring the effectiveness of pay and rewards: the Achilles' heel of contemporary rewards professionals', Compensation and Benefits Review, Vol. 40, No. 5, pp. $23-41$.

Bryson, A. et al. (2012) Paying for Performance: Incentive Pay Schemes and Employees' Financial Participation, Centre for Economic Performance, London School of Economics and Political Science, London.

Burton, D. (1991) 'Tellers into sellers?', International Journal of Bank Marketing, Vol. 9, No. 6, pp.25-29.

Cadsby, B.C., Song, F. and Tapon, F. (2010) 'Are you paying your employees to cheat? An experimental investigation', The BE Journal of Economic Analysis, Vol. 10, No. 1, pp.2-32.

Chebat, J-C., Babin, B. and Kollias, P. (2002) 'What makes contact employees perform? Reactions to employee perceptions of managerial practices', International Journal of Bank Marketing, Vol. 20, No. 7, pp.325-332.

Cheema, F-E-A., Shujaat, S. and Alam, R. (2013) 'Impact of non-monetary rewards on employees' motivation: a study of commercial banks in Karachi', Journal of Management and Social Sciences, Vol. 9, No. 2, pp.23-30.

Clason, D.L. and Dormody, T.J. (1994) 'Analyzing data measured by individual likert-type items', Journal of Agricultural Education, Vol. 35, No. 4, pp.31-35.

Coates, J., Davis, T. and Stacey, R. (1995) 'Performance measurement systems, incentive reward schemes and short-termism in multinational companies: a note', Management Accounting Research, Vol. 6, No. 2, pp.125-135.

Conrads, J., Irlenbusch, B., Rilke, R.M. and Walkowitz, G. (2013) 'Lying and team incentives', Journal of Economic Psychology, Vol. 34, pp.1-7.

Danilov, A., Biemann, T., Kring, T. and Sliwka, D. (2013) 'The dark side of team incentives: experimental evidence on advice quality from financial services professionals', Journal of Economic Behavior and Organization, Vol. 93, pp.266-272.

Denis, D.J., Hanouna, P. and Sarin, A. (2006) 'Is there a dark side to incentive compensation?', Journal of Corporate Finance, Vol. 12, No. 3, pp.467-488.

Dessler, G. (2013) Human Resource Management, 13th ed., Pearson/Prentice Hall, New Jersey. 
Dewhurst, M., Guthridge, M. and Mohr, E. (2009) 'Motivating people: getting beyond money', McKinsey Quarterly, Vol. 1, No. 4, pp.12-15.

Dunkley, E. (2014) Financial Times - TSB in Shake-up of Staff Rewards [online] http://www.ft.com/cms/s/0/06e4bf8c-ed5f-11e3-8a1e-00144feabdc0.html\#axzz3nU4pLpLm (accessed 26 March 2016).

Eisenberger, R. and Cameron, J. (1996) 'Detrimental effects of reward: reality or myth?', American Psychologist, Vol. 51, No. 11, pp.1153-1166.

European Commission (2015a) State Aid: Commission Approves Aid for National Bank of Greece on the Basis, European Commission, Brussels.

European Commission (2015b) State Aid: Commission Approves Aid for Piraeus Bank on the Basis of an Amended Restructuring Plan, European Commission, Brussels.

European Commission (2015c) State Aid: Commission Approves Amended Restructuring Plans for Alpha Bank and Eurobank, European Commission, Brussels.

Faisal Ahammad, M., Mook Lee, S., Malul, M. and Shoham, A. (2015) 'Behavioral Ambidexterity: the impact of incentive schemes on productivity, motivation, and performance of employees in commercial banks', Human Resource Management, Vol. 54, No. 1, pp.45-62.

Financial Conduct Authority (2013a) FCA - FCA Fines Lloyds Banking Group Firms A Total of $£ 28,038,800$ for Serious Sales Incentive Failings [online] http://www.fca.org.uk/news/pressreleases/fca-fines-lloyds-banking-group-firms-for-serious-sales-incentive-failings (accessed 26 March 2016).

Financial Conduct Authority (2013b) FCA Final Notice 2013: Lloyds TSB Bank Plc and Bank of Scotland Plc [online] http://www.fca.org.uk/your-fca/documents/final-notices/2013/lloyds-tsbbank-and-bank-of-scotland (accessed 26 March 2016).

Financial Services Authority (2013) Final Guidance. Risks to Customers from Financial Incentives, The Financial Services Authority, London.

Fischbacher, U. and Föllmi-Heusi, F. (2013) 'Lies in disquise - an experimental study on cheating', Journal of the European Economic Association, Vol. 11, No. 3, pp.525-547.

G20/OECD Task Force on Financial Consumer Protection (2013) Update Report on the Work to Support the Implementation of the G20 High-Level Principles on Financial Consumer Protection, Principles 4, 6 and 9, Organisation for Economic Co-operation and Development, Paris.

Gibbs, P.T. (1993) 'Customer care and service: a case for business ethics', International Journal of Bank Marketing, Vol. 11, No. 1, pp.26-33.

Gibson, R., Tanner, C. and Wagner, A.F. (2013) 'Preferences for truthfulness: heterogeneity among and within individuals', American Economic Review, Vol. 103, No. 1, pp.532-548.

Gilespie, N. and Dietz, G. (2009) 'Trust repair after an organization-level failure', Academy of Management Review, Vol. 34, No. 1, pp.127-145.

Gneezy, U., Rockenbach, B. and Serra-Garcia, M. (2013) 'Measuring lying aversion', Journal of Economic Behavior and Organization, Vol. 93, pp.293-300.

Goff, S. (2012) Financial Times [online] http://www.ft.com/cms/s/0/4fc20e54-1d1c-11e2-a17f00144feabdc0.html\#axzz3e6eICei2 (accessed 26 March 2016).

Greener, S. (2008) Business Research Methods, Ventus Publishing ApS, s.l.

Hassan, S., Hassan, M.U. and Shoaib, M. (2014) 'Measuring the impact of perceived organizational support, psychological empowerment and rewards on employees' satisfaction: testing the mediating impact of employee engagement', World Applied Sciences Journal, Vol. 30, No. 5, pp.652-660.

Holtmann, M. and Grammling, M. (2005) Designing and Implementing Staff Incentive Schemes, MicroSave, Lucknow.

Hyde, D. (2014) The Telegraph - Public 'Still at Risk' from Bank Sales Incentives [online] http://www.telegraph.co.uk/finance/personalfinance/bank-accounts/10675112/Public-still-atrisk-from-bank-sales-incentives.html (accessed 26 March 2016). 
Hyż, A. (2010) 'Job satisfaction and employee performance of Greek banking staff: an empirical investigation', Folia Oeconomica, Vol. 239, pp.85-96.

Inderst, R. and Ottaviani, M. (2009) 'Mis-selling through agents', The American Economic Review, Vol. 99, No. 3, pp.883-908.

Jamieson, S. (2004) 'Likert scales: how to (ab)use them', Medical Education, Vol. 38, No. 12, pp.1212-1218.

Jeffrey, S.A. and Wilches-Alzate, G. (2014) The Role of Rewards and Recognition in Customeroriented Citizenship Behaviors, p.14039, Academy of Management, Philadelphia.

Jehanzeb, K., Rasheed, M.F., Rasheed, A. and Aamir, A. (2012) 'Impact of rewards and motivation on job satisfaction in banking sector of Saudi Arabia', International Journal of Business and Social Science, Vol. 3, No. 21, pp.272-278.

Jenkins, D.G.J., Gupta, N., Mitra, A. and Shaw, J.D. (1998) 'Are financial incentives related to performance? A meta-analytic review of empirical research', Journal of Applied Psychology, Vol. 83, No. 5, pp.777-787.

Jonker, J. and Pennink, B.W. (2010) The Essence of Research Methodology, A Concice Guide for Master and PhD Students in Management Science, 1st ed., Springer, Berlin.

Lawler, E.E. (2005) 'Creating high performance organizations', Asia Pacific Journal of Human Resources, Vol. 43, No. 1, pp.10-17.

Lindley, D. (2014) Consumers International - Risky Business: The Case for Reform of Sales Incentives Schemes in Banks [online] http://www.consumersinternational.org/media/ 1517537/sales-incentive-report_riskybusiness_final2_151014.pdf (accessed 24 March 2016).

Locke, E.A. and Latham, G.P. (2004) 'What should we do about motivation theory? Six recommendations for the twenty-first century', Academy of Management Review, Vol. 29, No. 3, pp.388-403.

Malhotra, N., Budhwar, P. and Prowse, P. (2007) 'Linking rewards to commitment: an empirical investigation of four UK call centres', The International Journal of Human Resource Management, Vol. 18, No. 12, pp.2095-20128.

Mendoza, M.L. and Maldonado, C.O. (2014) 'Meta-analytic of the relationship between employee job satisfaction and customer satisfaction', Suma de Negocios, Vol. 5, No. 11, pp.4-9.

Nienaber, A-M., Hofeditz, M. and Searle, R.H. (2014) 'Do we bank on regulation or reputation? A meta-analysis and meta-regression of organizational trust in the financial services sector', International Journal of Bank Marketing, Vol. 32, No. 5, pp.367-407.

Omollo, P.A. (2015) 'Effect of motivation on employees performance of commercial banks in Kenya: a case study of Kenya commercial bank in Migori county', International Journal of Human Resource Studies, Vol. 5, No. 2, pp.87-103.

Papasolomou, I. and Vrontis, D. (2006) 'Building corporate branding through internal marketing: the case of the UK retail bank industry', Journal of Product and Brand Management, Vol. 15, No. 1, pp.37-47.

Payne, A., Holt, S. and Frow, P. (2000) 'Integrating employee, customer and shareholder value through an enterprise performance model: an opportunity for financial services', International Journal of Bank Marketing, Vol. 18, No. 6, pp.258-273.

Phelan, C. and Clement, D. (2009) Federal Reserve Bank of Minneapolis, Incentive Compensation in the Banking Industry: Insights from Economic Theory [online] https://www.minneapolisfed.org/research/economic-policy-papers/incentive-compensation-inthe-banking-industry-insights-from-economic-theory (accessed 23 March 2016).

Popova, V. (2010) 'What renders financial advisors less treacherous? On commissions and reciprocity', Jena Economic Research Papers, Vol. 36, pp.1-34.

Pratheepkanth, P. (2011) 'Reward system and its impact in employee motivation in commercial bank of Sri Lanka Plc', Global Journal of Management and Business Research, Vol. 11, No. 4. 
Priya, U.T. and Eshwar, S.T. (2014) 'Rewards, motivation and job satisfaction of employees in commercial banks - an investigative analysis', International Journal of Academic Research in Business and Social Sciences, Vol. 4, No. 4, pp.70-78.

Provopoulos, G.A. (2014) 'The Greek economy and banking system: recent developments and the way forward', Journal of Macroeconomics, Vol. 39, No. B, pp.240-249.

Saunders, M., Lewis, P. and Thornhill, A. (2009) Research Methods for Business Students, 5th ed., Pearson, Essex.

Schneider, B. and Bowen, D.E. (1985) 'Employee and customer perceptions of service in banks: replication and extension', Journal of Applied Psychology, Vol. 70, No. 3, pp.423-433.

Sharma, R. (2013) 'The impact of various components of compensation on the motivation level of employees - a comparative study of selected Indian public and private sector banks', International Journal of Application or Innovation in Engineering and Management, Vol. 2, No. 7, pp.511-516.

Skaggs, K.J., Dickinson, A.M. and O'Connor, K.A. (1991) 'The use of concurrent schedules to evaluate the effects of extrinsic rewards on "intrinsic motivation": a replication', Journal of Organizational Behavior Management, Vol. 12, No. 1, pp.45-83.

Umrani, W.A. and Mahwood, R. (2015) 'The combined effect of management support and reward reinforcement on the banks performance', Centre for Human Resource Studies, Kuala Lumpur.

Weinberger, T.E. (2005) 'Evaluating the effectiveness of an incentive plan design within company constraints', Compensation and Benefits Review, Vol. 37, No. 6, pp.27-33.

Wheatley, M. (2012) FSA - the Incentivisation of Sales Staff - are Consumers Getting a Fair Deal? [online] http://www.fsa.gov.uk/library/communication/speeches/2012/0905-mw.shtml (accessed 26 March 2016).

Yeates, C. and Eyers, J. (2016) The Sydney Morning Herald, Banks to Review Commissions, Whistleblower Protections [online] http://www.smh.com.au/business/banking-and-finance/ banks-to-review-commissions-whistleblower-protections-20160421-gobhuc.html (accessed 28 May 2016).

Zingheim, P.K. and Schuster, J.R. (2000) 'Compensation strategies: total rewards: pushing the pedal to the metal', Journal of Business Strategy, Vol. 21, No. 4, pp.15-17. 